\begin{tabular}{|c|l|}
\hline Title & X irradiation induces the proapoptotic state independent of the loss of clonogenic ability in Chinese hamster V 79 cells. \\
\hline Author(s) & I izuka, Daisuke; Inanami, O samu; Matsuda, A kira; Kashiwakura, Ikuo; A sanuma, Taketoshi; Kuwabara, Mikinori \\
\hline Citation & $\begin{array}{l}\text { Radiation Research, 164(1), 36-44 } \\
\text { https://doi.org/10.1667/RR3393 }\end{array}$ \\
\hline Issue Date & 2005-07 \\
\hline Doc URL & http://hdl.handle.net/2115/27973 \\
\hline Type & article \\
\hline File Information & RR1641.pdf \\
\hline
\end{tabular}

Instructions for use 


\title{
$X$ Irradiation Induces the Proapoptotic State Independent of the Loss of Clonogenic Ability in Chinese Hamster V79 Cells
}

\author{
Daisuke Iizuka, ${ }^{a}$ Osamu Inanami, ${ }^{a}$ Akira Matsuda, ${ }^{b}$ Ikuo Kashiwakura, ${ }^{c}$ Taketoshi Asanuma ${ }^{a}$ and Mikinori Kuwabara ${ }^{a, 1}$ \\ ${ }^{a}$ Laboratory of Radiation Biology, Graduate School of Veterinary Medicine, Hokkaido University, Sapporo, 060-0818, Japan; ${ }^{b}$ Laboratory of \\ Medicinal Chemistry, Graduate School of Pharmaceutical Sciences, Hokkaido University, Sapporo 060-8012, Japan; and c Department of \\ Radiological Technology, Hirosaki University School of Health Sciences, Hirosaki 036-8564, Japan
}

Iizuka, D., Inanami, O., Matsuda, A., Kashiwakura, I., Asanuma, T. and Kuwabara, M. X Irradiation Induces the Proapoptotic State Independent of the Loss of Clonogenic Ability in Chinese Hamster V79 Cells. Radiat. Res. 164, 36-44 (2005).

The clonogenic ability (reproductive cell death) of Chinese hamster V79 cells was measured after treatment with $X$ radiation and a newly developed anti-cancer drug, 1-(3-C-ethynyl- $\beta$-D-ribo-pentofuranosyl)cytosine (ECyd, TAS106). Amplification in the loss of clonogenicity was observed compared to that obtained for cells exposed to $\mathrm{X}$ rays alone. Addition of benzyloxycarbonyl-val-ala-asp-fluoromethylketone (Z-VADFMK), a broad-spectrum caspase inhibitor, attenuated the increased lethality, but the dose-response curve obtained was found to merely revert to that obtained for cells exposed to $\mathrm{X}$ rays alone. Flow cytometric analysis showed that the number of cells arrested at the $G_{2} / M$ phase by $X$ irradiation was decreased by co-treatment with TAS106, and instead the number of cells in the sub- $G_{1}$ phase increased. Western blot analysis proved that TAS106 treatment down-regulated the expression of the $G_{2} / M$ arrest-related proteins cyclin B1, phospho-CDC2 and WEE1. From these results, it was concluded that (1) no apoptosis was included in the dose-response curve obtained from cells exposed to $\mathrm{X}$ rays alone, (2) $\mathrm{X}$ radiation induced a potentially apoptotic (proapoptotic) state in cells independent of the loss of their clonogenic ability, and (3) TAS106 enhanced the loss of their clonogenic ability by converting the proapoptotic cells to apoptotic cells through the abrogation of arrest at the $\mathrm{G}_{2} / \mathrm{M}$ phase. $\odot 2005$ by Radiation Research Society

\section{INTRODUCTION}

Cell survival after exposure to ionizing radiation is generally judged by measuring the clonogenic ability of cells (reproductive death), and the dose-response curve is based on the relationship between the cell survival and the radiation dose. Both apoptosis and reproductive cell death are included in the loss of clonogenic ability. Since apoptosis

\footnotetext{
${ }^{1}$ Address for correspondence: Laboratory of Radiation Biology, Graduate School of Veterinary Medicine, Hokkaido University, Sapporo, 0600818, Japan; e-mail: kuwabara@vetmed.hokudai.ac.jp.
}

is regarded as a rare mechanism of mammalian cell death after exposure to ionizing radiation, except for apoptosissensitive cells like thymocytes, lymphocytes, and embryonal and undifferentiated progenitor stem cells $(1)$, the fraction of apoptosis may not generally be included in the dose-response curve. Chinese hamster V79 cells are resistant to apoptosis after exposure to ionizing radiation, but they show apoptosis when they are treated with relatively high concentrations of $\mathrm{H}_{2} \mathrm{O}_{2}$, suggesting that the mechanism of apoptosis is actually present in this cell line (2). However, it is possible that the resistance of this cell line to apoptosis after exposure to ionizing radiation does not necessarily mean that ionizing radiation does not induce the potentially apoptotic (proapoptotic) state. The proapoptotic state might not be reflected in the dose-response curve.

A combination of $\mathrm{X}$ radiation and an anticancer drug is sometimes employed for cancer treatment to improve the cure rate $(3,4)$. As expected, and as reported for human gastric adenocarcinoma MKN45 and MKN28 cells as well as murine rectum adenocarcinoma Colon 26 cells, we found that a newly developed anti-tumor drug, TAS106, which targets RNA synthesis, had the ability to enhance X-rayinduced cell death (5). In the present study, we applied this compound to apoptosis-resistant Chinese hamster V79 cells. Interestingly, when the cells were simultaneously treated with both X rays and TAS106, the induction of apoptosis was observed. Therefore, we inferred that (1) the proapoptotic state is induced in apoptosis-resistant Chinese hamster V79 cells by X radiation and (2) the proapoptotic state can be converted to apoptosis by co-treatment with the anti-cancer drug TAS106. To examine this hypothesis, flow cytometric and Western blot analyses were used to determine the mechanism of the conversion of the proapoptotic state to apoptosis by TAS106.

\section{MATERIALS AND METHODS}

Chemicals

$\alpha$-MEM was purchased from Invitrogen (Carlsbad, CA). TAS106 (ECyd) and its triphosphate form (1-[3-C-ethynyl- $\beta$-D-ribopentofuranosyl]cytosine triphosphate, ECTP) were synthesized and purified by one 
of authors (AM) according to the method reported previously $(6) .\left[{ }^{3} \mathrm{H}\right]-$ TAS106 (cytosine-5(n)- $\left[{ }^{3} \mathrm{H}\right], 37 \mathrm{kBq} / \mathrm{ml}$ ) was generated by Amersham Biosciences (Piscataway, NJ). Benzyloxycarbonyl-val-ala-aspfluoromethylketone (Z-VAD-FMK) was obtained from Peptide Institute (Osaka, Japan) and was dissolved in dimethyl sulfoxide (DMSO). Thymidine, cytidine, propidium iodide (PI) and ethidium bromide (EtB) were from Sigma Chemical Company (St. Louis, MO). RNase A was from Roche Diagnostics (Mannheim, Germany). Anti-cyclin B1 (D-11), antiWEE1 (C-20) and anti-actin (I-19) were from Santa Cruz Biotechnology (Santa Cruz, CA). Anti-phospho-CDC2 was from Cell Signaling Technology (Beverly, MA). The chemiluminescence detection kit, Western Lightning ${ }^{\mathrm{TM}}$ Chemiluminescence Reagent Plus, was from Perkin Elmer (Boston, MA).

\section{Cell Culture}

The Chinese hamster V79 cell line was a kind gift of Dr. H. Utsumi (Kyoto University Research Reactor Institute) and was grown in $\alpha$-MEM containing $10 \%$ fetal calf serum at $37^{\circ} \mathrm{C}$ in $5 \% \mathrm{CO}_{2} / 95 \%$ air.

\section{Treatments of Cells with Drugs and X Irradiation}

$\mathrm{X}$ irradiation was performed with an $\mathrm{X}$-ray generator $(1.0 \mathrm{~mm}$ aluminum filter, $200 \mathrm{kVp}, 20 \mathrm{~mA}$, Shimazu HF-320, Kyoto, Japan) at a dose rate of $3.9 \mathrm{~Gy} / \mathrm{min}$, which was determined by Fricke's chemical dosimeter. Treatments with TAS106, Z-VAD-FMK and cytidine were carried out by adding each compound to cells in growth medium at the indicated concentrations at $37^{\circ} \mathrm{C} 1 \mathrm{~h}$ before $\mathrm{X}$ irradiation. When synchronized cells were required for experiments, cell cycle synchronization was performed by the double-blocking technique with thymidine as described below. The synchronized cells were then treated with TAS106 and X irradiation at the same time. Cells were exposed to each drug for the indicated times.

\section{Clonogenic Assay}

One hundred to 30,000 cells were seeded on 6-cm Petri dishes (three replicates per dose) and treated with TAS106 and/or Z-VAD-FMK $4 \mathrm{~h}$ after seeding. After incubation with the drug for $1 \mathrm{~h}$, cells were exposed to $\mathrm{X}$ rays and incubated for $12 \mathrm{~h}$. Then the cells were washed with PBS-, placed in fresh medium, and cultured for 7 days. The cells were then fixed with methanol, stained with Giemsa stain, and scored under a microscope. Only colonies containing more than 50 cells were scored as surviving cells. After the surviving fraction at each dose was calculated with respect to the plating efficiency of the nonirradiated control, the mean \pm SEM of the surviving fractions obtained from four experiments was plotted.

\section{Fluorescence Microscope Observation of Apoptotic Cells}

Fluorescence microscope observation of apoptotic cells was performed as described previously (5). In brief, cells incubated for $12 \mathrm{~h}$ after X irradiation were collected. The pellet was washed in $\mathrm{Ca}^{2+}$ - and $\mathrm{Mg}^{2+}$-free phosphate-buffered saline PBS $^{-}$and fixed with $1 \%$ glutaraldehyde/PBSsolution. For fluorescence microscopy, the fixed cells were washed and resuspended in $20 \mu \mathrm{l}$ of $\mathrm{PBS}^{-}$including $40 \mu \mathrm{g} / \mu \mathrm{l}$ PI for $15 \mathrm{~min}$ in the dark. Fluorescence microscope observation was performed using an Olympus BX50 microscope (Olympus, Tokyo, Japan) with reflected-light fluorescence to count cells with chromatin condensation as apoptotic cells. The fraction of apoptotic cells is referred to as the percentage of apoptotic cells relative to the total cells observed microscopically. Four independent experiments were performed.

\section{Observation of Ladder-like DNA Fragmentation by Agarose Gel Electrophoresis}

Cells $\left(1 \times 10^{7}\right)$ incubated for $12 \mathrm{~h}$ after exposure to $\mathrm{X}$ rays and/or treatment with TAS106 were collected by centrifugation at $1,000 \mathrm{rpm}$ for
5 min at $4^{\circ} \mathrm{C}$. The pellet was washed with PBS. Assay of ladder-like DNA fragmentation was performed according to the method described previously (2). Briefly, lysis buffer $[0.2 \%$ Triton X-100, $10 \mathrm{mM}$ Tris- $\mathrm{HCl}$ (pH 7.4), $1 \mathrm{mM}$ EDTA ( $\mathrm{pH}$ 8.0)] was added to the pellet followed by centrifugation at $12,000 \mathrm{rpm}$ for $30 \mathrm{~min}$ at $4^{\circ} \mathrm{C}$. DNA was extracted from the supernatant using phenol/chloroform/isoamyl alcohol and was loaded on $2 \%$ agarose gels. DNA fragments separated in the gel were detected by staining with ethidium bromide.

\section{HPLC Analysis of Triphosphorylation of TAS106}

Cells $\left(2 \times 10^{7}\right) 12 \mathrm{~h}$ after treatment with $5 \mu M$ TAS106 including 37 $\mathrm{kBq}\left[{ }^{3} \mathrm{H}\right]-\mathrm{TAS} 106$ were collected by centrifugation at $1,000 \mathrm{rpm}$ for 5 $\min$ at $4^{\circ} \mathrm{C}$. The cells were washed with PBS- and deproteinized with 25 $\mu \mathrm{l}$ of $40 \%$ trichloroacetic acid and then disrupted with $200 \mu \mathrm{l}$ of $10 \%$ trichloroacetic acid. The precipitate was removed by centrifugation at $12,000 \mathrm{~g}$. One milliliter of diethyl ether was added to the supernatant, which was rigorously mixed with a vortex mixer. After being allowed to stand for a moment, the supernatant containing trichloroacetic acid was removed. This operation was repeated at least five times until the $\mathrm{pH}$ of the solution became 5 . The extract was analyzed by HPLC with an anionexchange column (TSK-gel DEAE-2SW, Tosoh Corporation, Tokyo, Japan) according to the method described by Takatori et al. (7). The extract was eluted with $100 \%$ buffer A $\left[10 \mathrm{mM} \mathrm{NH}_{4} \mathrm{H}_{2} \mathrm{PO}_{4}, 10 \mathrm{~m} M\right.$ sodium hexanesulfonate and $20 \% \mathrm{CH}_{3} \mathrm{CN}(\mathrm{pH} 3.0)$ ] at a flow rate of $1.0 \mathrm{ml} / \mathrm{min}$ for $10 \mathrm{~min}$ and subsequently with a linear gradient to $60 \%$ buffer B [80 $\mathrm{m} M \mathrm{Na}_{2} \mathrm{HPO}_{4}, 10 \mathrm{mM}$ hexanesulfonate and $20 \% \mathrm{CH}_{3} \mathrm{CN}$ (pH 6.0)] for $35 \mathrm{~min}$ and finally with $100 \%$ buffer B for $80 \mathrm{~min}$. The gradient program was controlled by an automated gradient controller (SC-8020, Tosoh) and the eluate was monitored at $260 \mathrm{~nm}$ with a UV detector (UV-8020, Tosoh). A fraction of $0.5 \mathrm{ml}$ was collected every $30 \mathrm{~s}$ and mixed with 10 $\mathrm{ml}$ of liquid scintillator (AQUASOL-2, Perkin Elmer), and the radioactivity of each fraction was measured with a liquid scintillation counter (TRI-CARB 2100TR, Perkin Elmer). Two independent experiments were performed; a representative chromatogram is shown in Fig. 2.

\section{Cell Cycle Synchronization by the Double-Blocking Technique with Thymidine}

Cells were synchronized by two treatments with an excess amount of thymidine essentially according to the method described by Stein et al. (8). Briefly, cells were treated with $2 \mathrm{~m} M$ thymidine for $8 \mathrm{~h}$, released for $4 \mathrm{~h}$ by washing three times with PBS $^{-}$, and treated again with $2 \mathrm{mM}$ thymidine for $8 \mathrm{~h}$. Synchronized cells were then treated with $\mathrm{X}$ radiation and/or TAS106 at the same time.

\section{Cell Cycle Analysis by Flow Cytometry}

Cell cycle analysis by flow cytometry was described previously (5). Cells were collected at the indicated times after $\mathrm{X}$ irradiation and fixed with $70 \%$ ethanol. The fixed cells were washed, suspended in PBS- including RNase A and incubated at $37^{\circ} \mathrm{C}$ for $30 \mathrm{~min}$. After centrifugation, the pellet was suspended in $1 \mathrm{ml}$ of PBS- containing PI at $50 \mu \mathrm{g} / \mu \mathrm{l}$. The DNA content in 10,000 cells was analyzed using an EPICS ALTRA flow cytometer (Beckman Coulter, Fullerton, CA). Three independent experiments were performed.

\section{SDS-PAGE and Western Blotting}

Cells were collected at the indicated time after $\mathrm{X}$ irradiation, and $5 \times$ $10^{6}$ cells were suspended in $75 \mu$ l of lysis buffer [ $20 \mathrm{mM}$ HEPES ( $\mathrm{pH}$ 7.4), $2 \mathrm{~m} M$ EGTA, $50 \mathrm{~m} M$ glycerophosphate, $1 \%$ Triton X-100, $10 \%$ glycerol, $1 \mathrm{~m} M$ PMSF] and kept on ice for $30 \mathrm{~min}$ and sonicated twice for $30 \mathrm{~s}$ at ice-cold temperature. After centrifugation at 12,000 rpm for $30 \mathrm{~min}$ at $4^{\circ} \mathrm{C}$, a threefold volume of Laemmli's sample buffer [187.5 $\mathrm{m} M$ Tris- $\mathrm{HCl}$ (pH 6.8), 30\% glycerol, $15 \%$ $\beta$-mercaptoethanol, $4 \%$ SDS, $0.004 \%$ bromophenol blue] was added to the supernatant, which was then 
boiled for 3 min. Proteins were separated by SDS-PAGE and transferred onto nitrocellulose membranes (ADVANTEC Toyo, Tokyo, Japan). The membranes were probed with anti-cyclin B1, anti-phospho-CDC2, antiWEE1 or anti-actin in TBST buffer $(10 \mathrm{mM}$ Tris-HCl, $0.1 \mathrm{M} \mathrm{NaCl}, 0.1 \%$ Tween-20, pH 7.4) containing 5\% nonfat skim milk or 5\% BSA. These antibodies were detected by a method using HRP-conjugated anti-rabbit, anti-mouse or anti-goat IgG antibodies with Perkin Elmer Western Lightning ${ }^{\mathbb{N}}$, Chemiluminescence Reagent Plus. Two independent experiments were performed. A representative pattern is shown in Fig. 5. The bands were quantified by NIH Image analysis.

\section{Statistics}

After the necessary data had been collected $(n=4)$, statistical analyses were performed using Microsoft Excel with the Statcel2 statistical addon package (OMS Co., Tokyo, Japan). The results were given as means \pm SD. The statistical significance of differences between the groups was tested with the Mann-Whitney $U$ test. $P<0.05$ was accepted as statistically significant.

\section{RESULTS}

Effects of TAS106 on Cell Survival Judged by Clonogenic Ability and Apoptosis

Figure 1A shows the cytotoxicity of TAS106 in Chinese hamster V79 cells as determined by their clonogenicity. Since more than $60 \%$ of cells survived at the concentration of $1.0 \mu M$ TAS106, we employed this concentration for subsequent experiments. Figure $1 \mathrm{~B}$ shows the X-ray doseresponse curves of Chinese hamster V79 cells judged by their clonogenic abilities in the presence and absence of TAS106. The surviving fractions in the presence of TAS106 were corrected for its cytotoxicity at $1 \mu M$. Fitting of dose-response curves to experimental measurements was performed by using the computer program Origin $6.1 \mathrm{~J}$ (OriginLab Corp., Northampton, MA). When each survival curve was fitted by the linear-quadratic model, the $\alpha$ and $\beta$ values for $\mathrm{X}$ rays alone and X rays + TAS106 were calculated. The $\alpha$ values for $\mathrm{X}$ rays alone and $\mathrm{X}$ rays + TAS106 were $0.036 \pm 0.010$ and $0.084 \pm 0.001$, respectively. The difference between these two values was small but statistically significant. For the $\beta$ values, $0.015 \pm 0.001$ for $\mathrm{X}$ rays alone and $0.016 \pm 0.001$ for $\mathrm{X}$ rays + TAS106 were calculated, and there were no significant differences between these two groups. The $\alpha_{(\mathrm{X} \text { rays }}+$ TAS106 $/ \alpha_{(\mathrm{X} \text { rays })}$ and $\beta_{(\mathrm{X} \text { rays }}+\mathrm{TAS}_{106)} / \beta_{(\mathrm{X} \text { rays })}$ were 2.3 and 1.1 , respectively. Comparison of the two dose-response curves proved that TAS106 enhanced the reproductive cell death in X-irradiated Chinese hamster V79 cells to a small extent with a significant difference. When a broad-spectrum caspase inhibitor (Z-VAD-FMK) was added to the culture before $\mathrm{X}$ irradiation, the dose-response curve was found to revert to that for cells treated with $X$ rays alone. Furthermore, the treatment with Z-VAD-FMK did not change the surviving fraction of cells treated with $\mathrm{X}$ radiation alone (data not shown). To confirm the induction of apoptosis, the ladderlike DNA fragmentation and morphological changes in cells were examined by agarose gel electrophoresis and fluorescence microscopy, respectively, as shown in Fig. 1D and E. No DNA fragmentation was observed in the case of $\mathrm{X}$ radiation alone. However, when cells were co-treated with X radiation and TAS106, fragmented DNA appeared. Addition of the caspase inhibitor Z-VAD-FMK attenuated the appearance of the ladder (Fig. 1D). Figure 1C shows fluorescence microscope observation of the morphological changes in nuclei, including DNA fragmentation and chromatin condensation. Quantitative measurements of apoptotic cells with fluorescence microscopy revealed that cotreatment of cells with X radiation and TAS106 resulted in an increase to about $17 \%$ of cells in the induction of apoptosis, which was higher than that of cells treated with either X rays or TAS106 alone. Z-VAD-FMK suppressed the induction of apoptosis to the level seen after $\mathrm{X}$ irradiation alone, indicating that TAS106 enhanced the killing efficiency of X rays in Chinese hamster V79 cells by inducing apoptosis (Fig. 1E). The dose of $1 \mu M$ TAS106 used in these experiments was optimal for the enhancement of cell killing as revealed by clonogenicity and the increase in apoptosis, because at a higher concentration $(10 \mu M)$ the drug became toxic and there was no further radiosensitization. In contrast, a low dose, $0.1 \mu M$ of TAS106, did not show any radiosensitization. Treatment of the cells with TAS106 beginning $3 \mathrm{~h}$ after irradiation and containing for $9 \mathrm{~h}$, with resulted in an increase in the induction of apoptosis to about $12 \%$ of cells (data not shown).

Addition of a high concentration of cytidine $(100 \mu M)$ abolished the enhancement of apoptosis by TAS106 (Fig. 1E). This suggests that TAS106 is phosphorylated by uridine/cytidine kinase (UCK) and that its phosphorylation is a prerequisite for its activity as a radiosensitizing agent.

\section{Phosphorylation of TAS106 by Uridine/Cytidine Kinase (UCK)}

Since cytidine abolished the enhancing effect of TAS106, the metabolism of TAS106 in the presence or absence of cytidine was analyzed by HPLC with an anion-exchange column. Figure 2A shows an HPLC profile obtained from control cells. Cytidine 5'-triphosphate and deoxycytidine 5 '-triphosphate (CTP and dCTP) were found to elute at around $49 \mathrm{~min}$. No radioactivity was observed from $46 \mathrm{~min}$ to $56 \mathrm{~min}$ (Fig. 2A, inset). Figure 2B shows an elution profile obtained from cells treated with $5 \mu M$ TAS106. In addition to peaks of CTP and $\mathrm{dCTP}$, a new peak corresponding to ethynylcytidine triphosphate (ECTP) appeared at $51 \mathrm{~min}$. At $51 \mathrm{~min}$, radioactivity was observed (Fig. 2B, inset). The elution time of ECTP was confirmed by detection of radioactivity at $51 \mathrm{~min}$. When cells were treated with X rays, TAS106 and cytidine, the peak of ECTP and radioactivity disappeared (Fig. $2 \mathrm{C}$ and inset). These results proved that TAS106 was phosphorylated by UCK in Chinese hamster V79 cells. The phosphorylation of TAS106 seems essential for its pharmacological activity. 
A

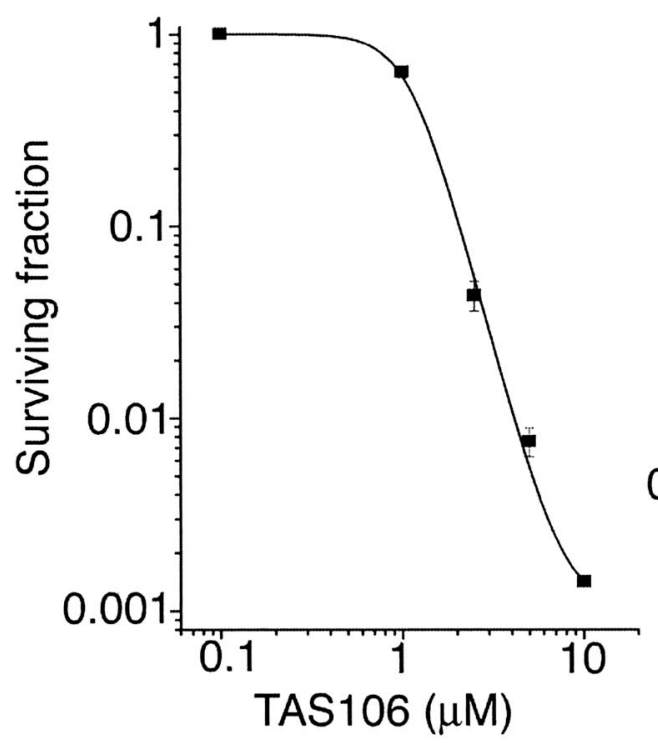

C
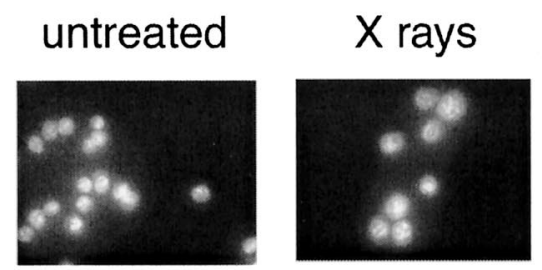

D

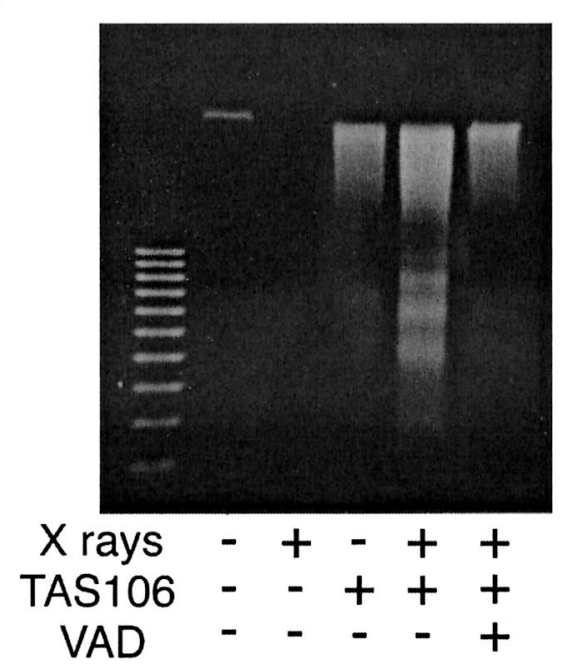

B

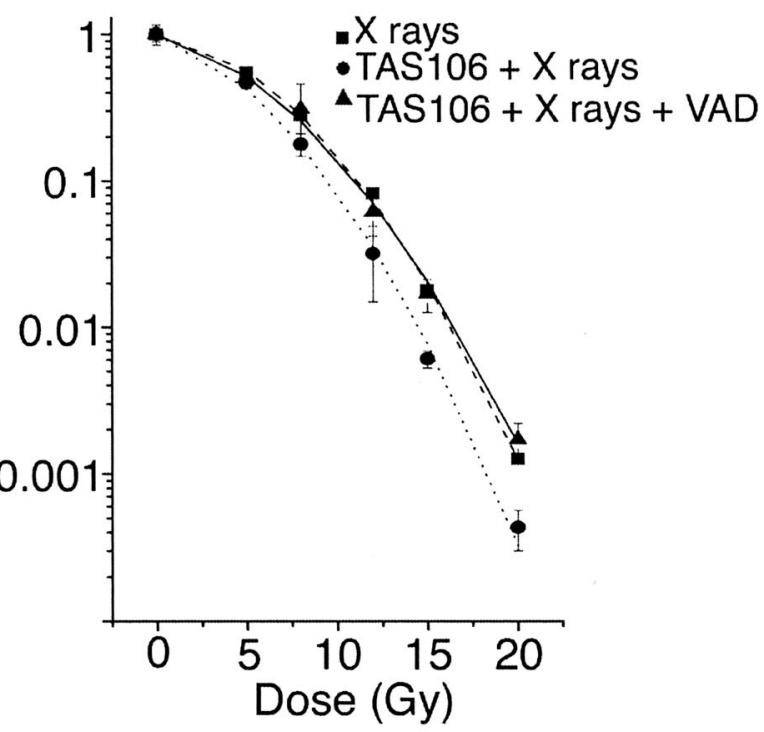

TAS106 TAS106 $+X$ rays
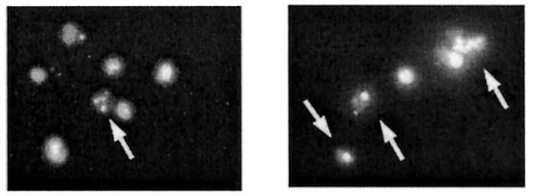

$E$

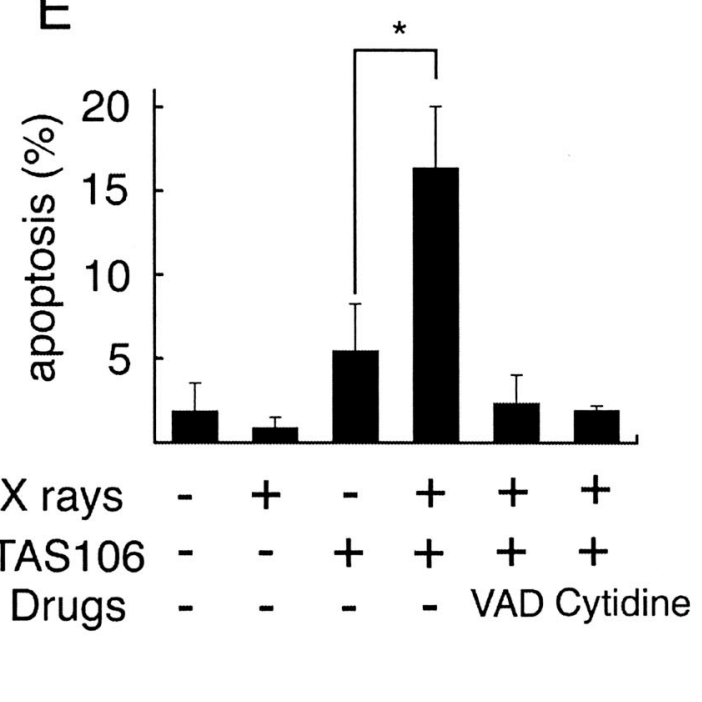

FIG. 1. Panel A: Concentration dependence of the cytotoxicity of TAS106 to Chinese hamster V79 cells. Cells were cultured for $12 \mathrm{~h}$ after treatment with 0.1-10 $\mu M$ TAS106 and incubated for 7 days for colony formation. Panel B: Dose-response curves for X-irradiated V79 cells: $(\square)$ X irradiation, $(\mathbf{)}$ X irradiation in the presence of $1 \mu M$ TAS106, and ( $\mathbf{\Delta}) \mathrm{X}$ irradiation in the presence of $1 \mu M$ TAS106 and $50 \mu M$ Z-VAD-FMK (VAD). Data are expressed as means \pm SD for four experiments. Panel C: Fluorescence microscopic observation of morphological changes indicative of apoptosis in nuclei of cells that were untreated, treated with $20 \mathrm{~Gy}$ of X rays, treated with $1 \mu M$ TAS106, and treated with 20 Gy of X rays and $1 \mu M$ TAS106 after staining with propidium iodide. White arrows indicated apoptotic cells including nuclear condensation. Panel D: Agarose gel electrophoresis of DNAs obtained from cells treated with 20 Gy of $\mathrm{X}$ rays, treated with $1 \mu M$ TAS106, and treated with 20 Gy of $\mathrm{X}$ rays and $1 \mu M$ TAS106. Panel E: Apoptosis induction (\%) measured by fluorescence microscopy after staining with propidium iodide in cells treated with 20 Gy of X rays, treated with $1 \mu M$ TAS106, treated with 20 Gy of X rays and $1 \mu M$ TAS106, treated with 20 Gy of X rays, $1 \mu M$ TAS106 and $50 \mu M$ Z-VAD-FMK, and treated with 20 Gy of $\mathrm{X}$ rays, $1 \mu M$ TAS106 and $50 \mu M$ cytidine. Each point represents the mean $\pm \mathrm{SD}$ of four different experiments. ${ }^{*} P<0.05$, Mann-Whitney $U$ test. 


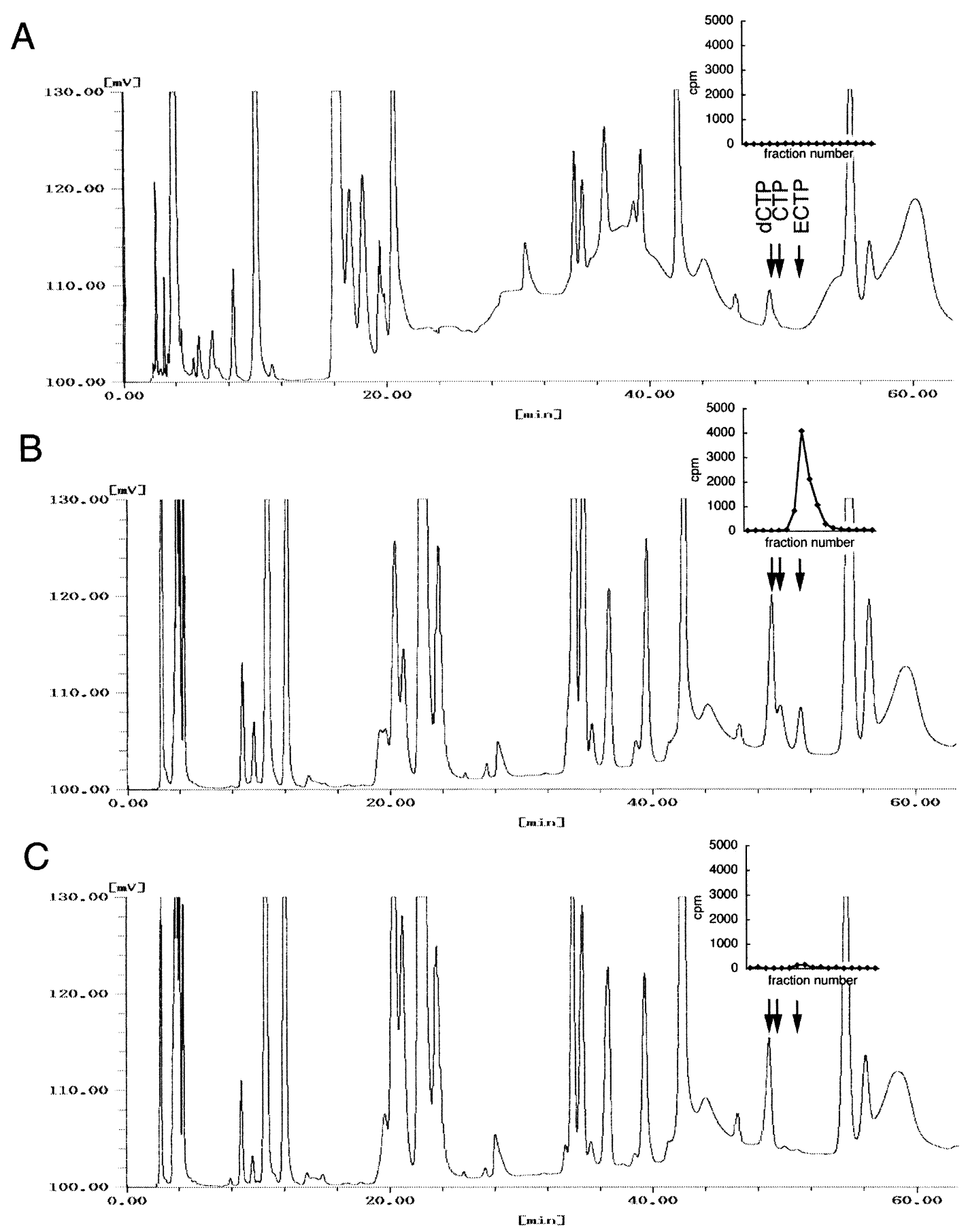

FIG. 2. HPLC elution profiles of extracts from V 79 cells (panel A) without treatment, (panel B) treated with 5 $\mu M$ TAS106, and (panel C) treated with 20 Gy of X rays, $5 \mu M$ TAS106 and $50 \mu M$ cytidine. Insets: radioactivity (count per minute) of $\left[{ }^{3} \mathrm{H}\right]$-TAS106 was counted for $30 \mathrm{~s}$.

Effects of X Radiation and TAS106 on Cell Cycle Distribution in Asynchronous and Synchronous Cells

Mammalian cells exhibit days in progression through the cell cycle at checkpoints in the $\mathrm{G}_{1} / \mathrm{S}, \mathrm{G}_{2} / \mathrm{M}$ and $\mathrm{M}$ phases when DNA damage is induced by $\mathrm{X}$ radiation (9-12). Various molecules are known to participate in these cell cycle checkpoints. These molecules are also thought to be correlated with cell survival and probably with apoptosis.
Therefore, it is of interest to investigate whether TAS106 modifies the function of cell cycle checkpoints after $\mathrm{X}$ irradiation. Figure 3A shows flow cytometric analysis of the effects of $\mathrm{X}$ radiation, TAS106, and $\mathrm{X}$ radiation plus TAS106 on the cell cycle distribution of asynchronous cells. When cells were exposed to $20 \mathrm{~Gy}$ of $\mathrm{X}$ rays and incubated for $12 \mathrm{~h}$, the flow cytometric profile showed a marked increase in the $G_{2} / M$-phase fraction, suggesting that 
A
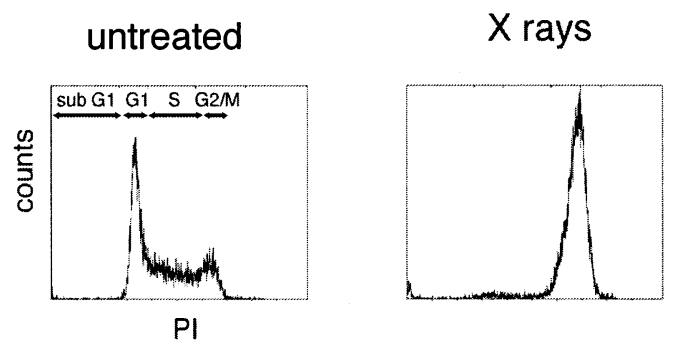

TAS106 $+X$ rays

B

0

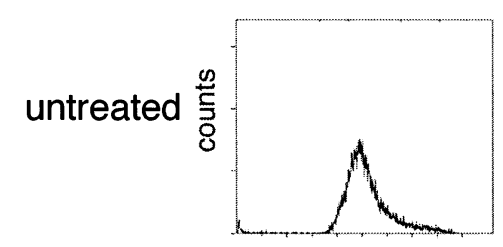

$\mathrm{Pl}$

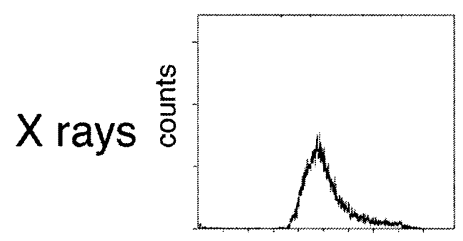

$\mathrm{Pl}$

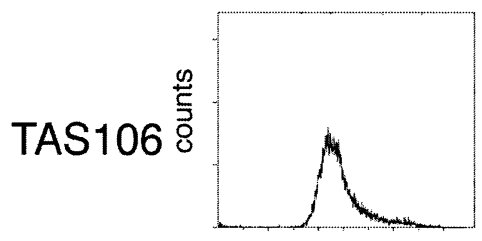

$\mathrm{PI}$

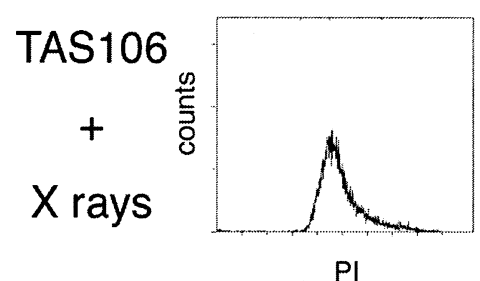

4
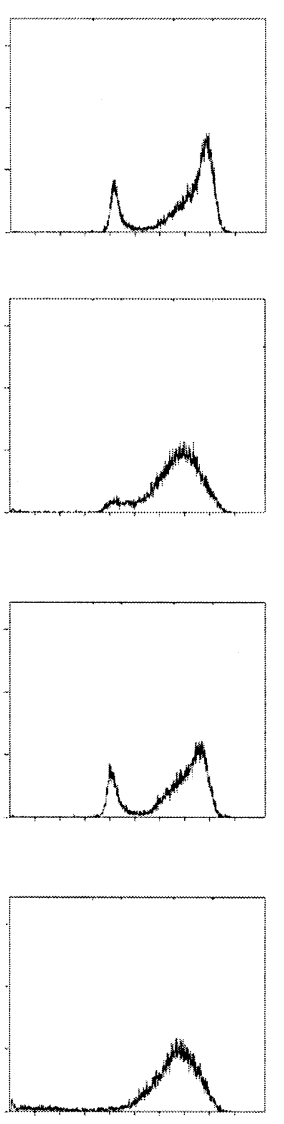

8
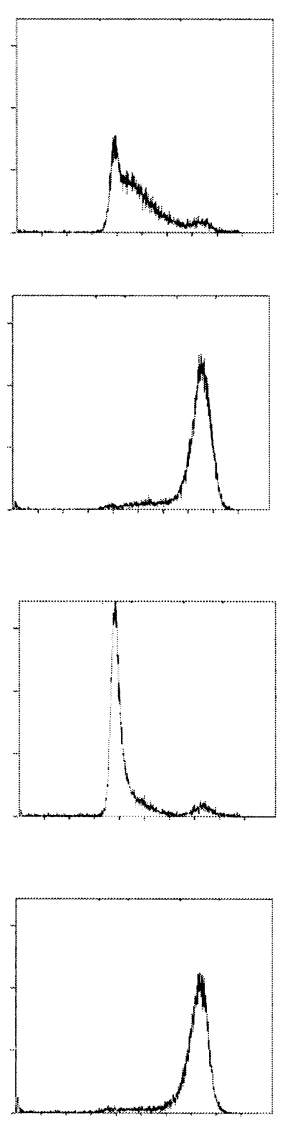

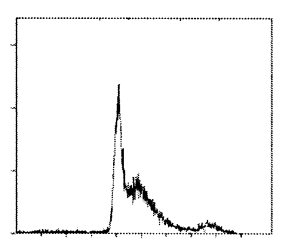

$12(\mathrm{~h})$
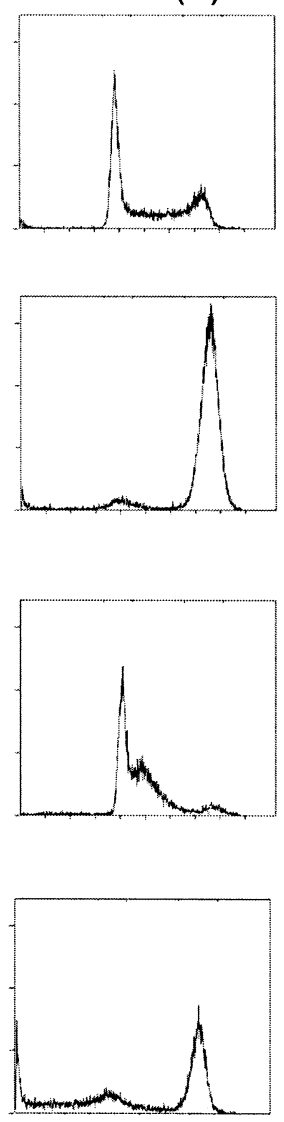

FIG. 3. Flow cytometric profiles of cell cycle distribution. Panel A: Asychronous V79 cells without treatment, treated with 20 Gy of X rays, and treated with 20 Gy of X rays and $1 \mu M$ TAS106. Panel B: Synchronized V79 cells without treatment, treated with $20 \mathrm{~Gy}$ of $\mathrm{X}$ rays, treated with $1 \mu M$ TAS106, and treated with 20 Gy of X rays and $1 \mu M$ TAS106. Profiles were taken at $0,4,8$ and $12 \mathrm{~h}$ after treatments. The $X$ axis and $Y$ axis indicate the DNA content and the number of cells, respectively. Experimental details are described in the text.

radiation-induced $\mathrm{G}_{2} / \mathrm{M}$ arrest occurred. The treatment with both $\mathrm{X}$ rays and TAS106 resulted in a decrease in the $\mathrm{G}_{2} / \mathrm{M}$ fraction and an increase in the sub- $\mathrm{G}_{1}$ fraction (apoptotic fraction), indicating that apoptosis was induced accompanied by the abrogation of $\mathrm{G}_{2} / \mathrm{M}$ arrest.

To further confirm the results, synchronized cells were prepared by a double-blocking technique with thymidine and studied. Figure 3B shows flow cytometric profiles of synchronized cells treated with $\mathrm{X}$ radiation, TAS106, and $\mathrm{X}$ radiation plus TAS106. Figure 4 shows the quantification of the cell cycle distributions. In the flow cytometric profile of synchronized, untreated cells at $0 \mathrm{~h}$, a sizable fraction of cells in the S phase was observed (Fig. 3B), although the treatment using this double-blocking technique with 


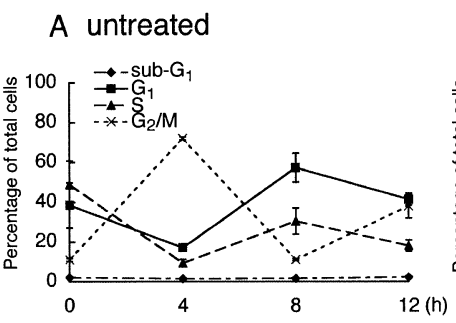

\section{B $X$ rays}

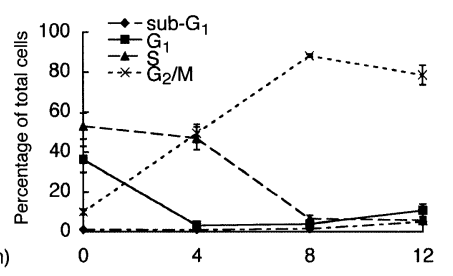

C TAS106

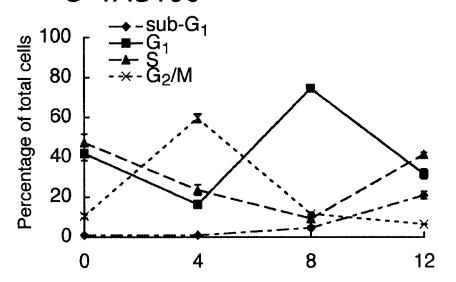

D TAS106 + $X$ rays

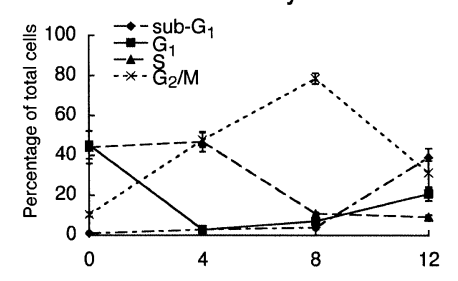

$\mathrm{E}$

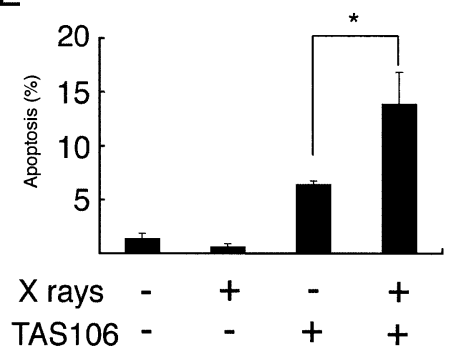

FIG. 4. Time course of cell cycle distributions after release of V79 cells from thymidine synchronization (panel A) untreated control, (panel B) 20 Gy of X rays, (panel C) $1 \mu M$ TAS106, and (panel D) 20 Gy of $\mathrm{X}$ rays and $1 \mu M$ TAS106. Each point represents the mean $\pm \mathrm{SD}$ of four different experiments. Panel E: Apoptosis induction (\%) measured by fluorescence microscopy after staining with propidium iodide in control cells and cells treated with 20 Gy of X rays, treated with $1 \mu M$ TAS106 and treated with $20 \mathrm{~Gy}$ of $\mathrm{X}$ rays and $1 \mu M$ TAS106 for $12 \mathrm{~h}$ after release of thymidine synchronization. Each point represents the mean $\pm \mathrm{SD}$ of four different experiments. ${ }^{*} P<0.05$, Mann-Whitney $U$ test.

thymidine was reported to synchronize cells at the $\mathrm{G}_{1} / \mathrm{S}$ phase border (13). After cells were unblocked by replacing the medium with fresh medium, they were further incubated for 4,8 and $12 \mathrm{~h}$. The profile of nonirradiated cells at 12 $\mathrm{h}$ proved to be the same as that of asynchronous cells. Cells $\mathrm{X}$-irradiated with 20 Gy accumulated in the $\mathrm{G}_{2} / \mathrm{M}$ fraction and remained there even $12 \mathrm{~h}$ after irradiation $\left(\mathrm{G}_{2}\right.$ fraction; 83\%). In TAS106-treated cells, cell cycle progression remained virtually the same as that of the nonirradiated controls or perhaps slightly slower. When $\mathrm{X}$-irradiated cells were treated with TAS106, the $\mathrm{G}_{2} / \mathrm{M}$ fraction increased up to $8 \mathrm{~h}$ but was decreased at $12 \mathrm{~h}$ compared with that for $\mathrm{X}$ radiation alone. Instead, the sub- $\mathrm{G}_{1}$ fraction appeared and was increased up to $12 \mathrm{~h}$ after treatment. This fraction was regarded as apoptotic cells and was about $40 \%$ of total cells. This value was significantly higher than that for $\mathrm{X}$ radiation alone (about 5\%) or TAS106 treatment alone (about 20\%) as shown in Fig. 4B, C and D. Since the sub$\mathrm{G}_{1}$ fraction in flow cytometry with PI staining sometimes contains DNA debris that is not from apoptotic cells, the cells were also examined with fluorescence microscopy and those showing apoptosis morphologically were counted. The results are shown in Fig. 4E. The values were relatively lower than those obtained by flow cytometry, suggesting that the sub- $\mathrm{G}_{1}$ fraction also contains other DNA debris. However, statistical analysis of the data proved that TAS106 significantly enhanced the induction of apoptosis in synchronized cells exposed to $\mathrm{X}$ rays and incubated for $12 \mathrm{~h}$. Therefore, it was concluded that TAS106 accelerated the induction of apoptosis by abrogating cell cycle arrest at the $\mathrm{G}_{2} / \mathrm{M}$ phase.

\section{Effects of X Radiation and TAS106 on the Expression of Cyclin B1, Phospho-CDC2 and WEE1}

Cyclin B1, phospho-CDC2 and WEE1 are highly expressed during the $\mathrm{G}_{2} / \mathrm{M}$ phase in a cell cycle-dependent manner as $G_{2} / M$ checkpoint-related proteins. When cells were exposed to genotoxic $\mathrm{X}$ rays, the accumulation of cyclin B1 and WEE1 and the phosphorylation of CDC2 at the $G_{2} / M$ phase become important signals for the $G_{2} / M$ checkpoint in response to DNA damage (14). Figure 5A shows the results of Western blot analysis of cell cycledependent accumulation of cyclin B1 and WEE1 and phosphorylation of CDC2 (phospho-CDC2) in nonirradiated, synchronized cells. High expression of these proteins was observed at $4 \mathrm{~h}$ and low expression was observed at 8 and $12 \mathrm{~h}$ after cells were unblocked. Quantification of these bands also supported cell cycle-dependent accumulation (cyclin B1, Fig. 5E; phospho-CDC2, Fig. 5F; WEE1, Fig. $5 \mathrm{G})$. Figure 5B shows the results for X-irradiated cells. Accumulation of cyclin B1, WEE1 and phospho-CDC2, which are essential for the cell cycle arrest at the $\mathrm{G}_{2} / \mathrm{M}$ phase, was observed at 8 and $12 \mathrm{~h}$. Figure 5C shows the results for cells treated with TAS106 alone. TAS106 treatment strongly diminished the accumulation of cyclin B1 and WEE1 and phospho-CDC2 at 8 and $12 \mathrm{~h}$. Figure 5D shows the results for cells treated with $\mathrm{X}$ radiation and TAS106. Treatment with TAS106 suppressed accumulation of cyclin B1, phospho-CDC2 and WEE1 compared with $\mathrm{X}$ radiation alone (Fig. 5D). These results were quite consistent with the flow cytometric profiles shown in Fig. 3B and indicated that TAS106 converted X-irradiated cells from the proapoptotic state to apoptosis by down-regulating the expression of $\mathrm{G}_{2} / \mathrm{M}$ arrest-related and probably apoptosis-related proteins like cyclin B1, phospho-CDC2 and WEE1.

\section{DISCUSSION}

Recent studies have reported a correlation between the enhancement of the X-ray killing effect and abrogation of the cell cycle checkpoint. For example, 7-hydroxystaurosporine (UCN-01) was reported to enhance the antitumor activity of ionizing radiation by inhibiting checkpoint kinase 1 (CHK1) (15-18). Caffeine is also known to be a radiosensitizing agent that attenuates the radiation-induced $\mathrm{G}_{2}$ checkpoint by inhibiting the radiation-induced activation 


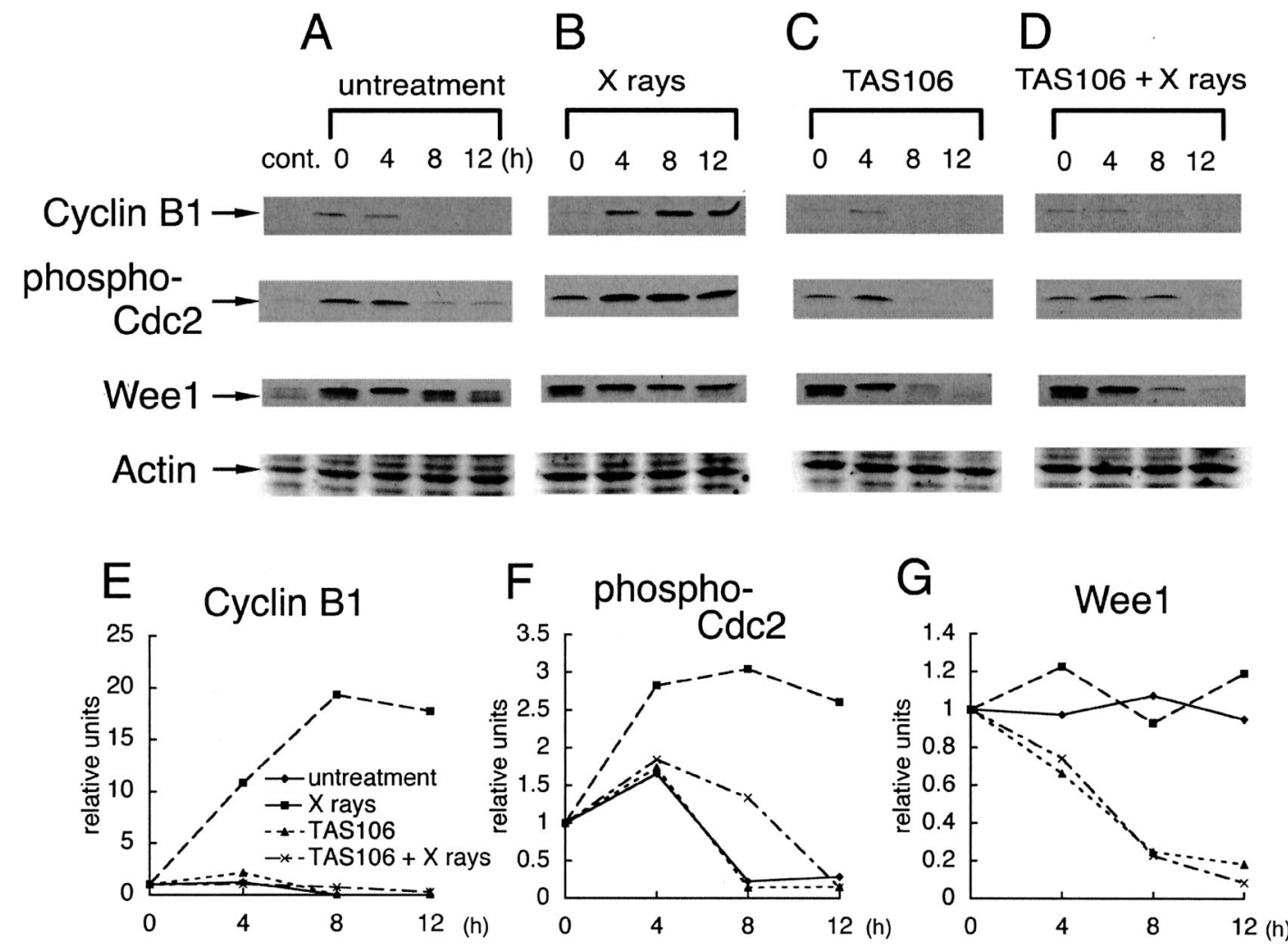

FIG. 5. Western blot analysis of the expression of cyclin B1, phospho-CDC2 and WEE1 using corresponding antibodies. Synchronous V79 cells (panel A) treated with $20 \mathrm{~Gy}$ of X rays (panel B), $1 \mu \mathrm{M}$ TAS106 (panel C), and 20 Gy of X rays and $1 \mu M$ TAS106 (panel D) were incubated for 0 to $12 \mathrm{~h}$. Actin was used as a standard. Quantification of bands of cyclin B1 (panel E), phospho-CDC2 (panel F) and WEE1 (panel G) was performed using NIH Image analysis normalized by actin.

of ataxia telangiectasia mutated (ATM) and ataxia telangiectasia mutated and Rad3-related (ATR) (18-20).

TAS106 is a newly developed anti-tumor drug targeting RNA synthesis (21). It is phosphorylated by UCK, which is essential for its cytotoxicity. It has been reported that UCK is widely distributed in tumor cells but not in normal cells (22). Our previous study has demonstrated that induction of apoptosis is enhanced by combining $\mathrm{X}$ radiation and a low dose of TAS106 in human gastric adenocarcinoma MKN45 cells with wild-type TP53 and MKN28 cells with TP53 mutation (5). MKN28 cells are known to have low sensitivity to 5FU in comparison with MKN45 cells (23). In the present study, we examined whether TAS106 could enhance the killing effects of $\mathrm{X}$ rays in Chinese hamster V79 cells with mutant TP53 (24). As shown in Fig. 1, X rays alone induced no apoptosis in this cell line, and the treatment of X-irradiated cells with TAS106 enhanced the reproductive cell death. When a broad-spectrum caspase inhibitor (Z-VAD-FMK) was added to the culture before $\mathrm{X}$ irradiation, the induction of apoptosis was almost completely inhibited, but the dose-response curve reverted to that obtained for cells irradiated with X rays alone. From these results it was suggested that (1) TAS106 enhanced the cell killing efficiency of $\mathrm{X}$ rays by inducing apoptosis regardless of the TP53 status, (2) X radiation induced a proapop- totic state that was not distinctly reflected in the dose-response curve but was converted to apoptosis by TAS106 treatment, and (3) the resulting apoptosis contributed to the enhancement of reproductive cell death. The results shown in Figs. 3 and 5 indicate that TAS106 accelerates the induction of apoptosis by abrogating the cell arrest at the $\mathrm{G}_{2} / \mathrm{M}$ phase through down-regulation of the expression of cyclin B1, WEE1 and phospho-CDC2.

The magnitude of radiosensitization by TAS106 was small, as shown in Fig. 1B. This may be due to the fact that the enhancement of X-ray killing effects by TAS106 is only a reflection of the induction of apoptosis. However, it is undeniable that the proapoptotic state was actually induced by $\mathrm{X}$ radiation in Chinese hamster V79 cells but not reflected in the original dose-response curve. The conversion to apoptosis by TAS106 was found to occur in cells of four mammalian cell lines, human gastric adenocarcinoma MKN45 (p53 wild-type), MKN28 (TP53 mutation), murine rectum adenocarcinoma Colon26 (TP53 status unknown) (5), and Chinese hamster V79 (TP53 mutation), with differential TP53 status. This may indicate the advantage of combination treatment with radiation and an anticancer drug like TAS106 over radiation treatment alone for radioresistant, TP53-mutated tumors. 


\section{ACKNOWLEDGMENTS}

This work was supported in part by Grants-in-Aid for Basic Scientific Research from the Ministry of Education, Culture, Sports, Science and Technology of Japan No. 15380199 (OI), No. 14636111 (OI), and No. 15025202 (MK) and the Akiyama Foundation (MK).

Received: August 30, 2004; accepted: February 28, 2005

\section{REFERENCES}

1. D. J. Allan, Radiation-induced apoptosis: Its role in a MADCaT (mitosis-apoptosis-differentiation-calcium toxicity) scheme of cytotoxicity mechanisms. Int. J. Radiat. Biol. 62, 145-152 (1992).

2. W. Hiraoka, K. Fuma and M. Kuwabara, Concentration-dependent modes of cell death in Chinese hamster V79 cells after treatments with $\mathrm{H}_{2} \mathrm{O}_{2}$. J. Radiat. Res. 38, 95-102 (1997).

3. K. Satyamoorthy, T. Bogenrieder and H. Meenhard, No longer a molecular black box-new clues to apoptosis and drug resistance in melanoma. Trends Mol. Med. 7, 191-194 (2001).

4. C. J. McGinn, T. S. Lawrence and M. M. Zalupski, On the development of gemcitabine-based chemoradiotherapy regimens in pancreatic cancer. Cancer 95, 933-940 (2002).

5. O. Inanami, D. Iizuka, A. Iwahara, Y. Kon, T. Asanuma, A. Matsuda, K. Kitazato and M. Kuwabara, A novel anticancer ribonucleoside, 1(3-C-ethynyl- $\beta$-ribo-pentofuranosyl) cytosine, enhances radiation-induced cell death in tumor cells. Radiat. Res. 162, 635-645 (2004).

6. H. Hattori, M. Tanaka, M. Fukushima, T. Sasaki and A. Matsuda, 1(3-C-ethynyl- $\beta$-D-ribo-pentofuranosyl)cytosine, 1-(3-C-ethynyl- $\beta$-Dribo-pentofuranosyl)uracil, and their nucleobase analogues as new potential multifunctional antitumor nucleosides with a broad spectrum of activity. J. Med. Chem. 39, 5005-5011 (1996).

7. S. Takatori, H. Kanda, K. Takenaka, Y. Wataya, A. Matsuda, M. Fukushima, Y. Shimamoto, M. Tanaka and T. Sasaki, Antitumor mechanisms and metabolism of the novel antitumor nucleoside analogues, 1-(3-C-ethynyl- $\beta$-D-ribo-pentofuranosyl) cytosine and 1-(3C-ethynyl- $\beta$-D-ribo-pentofuranosyl)uracil. Cancer Chemother. Pharmacol. 44, 97-104 (1999).

8. G. S. Stein, J. L. Stein, J. B. Lian, T. J. Last, T. Owen and L. McCabe, Synchronization of normal diploid and transformed mammalian cells. In Cell Biology, a Laboratory Handbook, Vol. 1 (J. E. Celis, Ed.), pp. 282-287. Academic Press, San Diego, 1994.

9. R. G. Bristow, S. Benchimol and R. P. Hill, The p53 gene as a modifier of intrinsic radiosensitivity: Implications for radiotherapy. Radiother. Oncol. 40, 197-223 (1996).

10. S. A. Amundson, T. G. Myers and A. J. Fornace, Jr., Roles for p53 in growth arrest and apoptosis: Putting on the brakes after genotoxic stress. Oncogene 17, 3287-3299 (1998).
11. T. Weinert, DNA damage and checkpoint pathways: Molecular anatomy and interactions with repair. Cell 94, 555-558 (1998).

12. C. Cadwell and G. P. Zambetti, The effects of wild-type p53 tumor suppressor activity and mutant p53 gain-of-function on cell growth. Gene 277, 15-30 (2001).

13. W. Krek and J. A. DeCaprio, Cell synchronization. Methods Enzymol. 254, 114-124 (1995).

14. K. K. Khanna, M. F. Lavin, S. P. Jackson and T. D. Mulhern, ATM, a central controller of cellular responses to DNA damage. Cell Death Differ. 8, 1052-1065 (2001).

15. L. C. Playle, D. J. Hicks, D. Qualtrough and C. Paraskeva, Abrogation of the radiation-induced $\mathrm{G}_{2}$ checkpoint by the staurosporine derivative $\mathrm{UCN}-01$ is associated with radiosensitisation in a subset of colorectal tumour cell lines. Br. J. Cancer 87, 352-358 (2002).

16. A. M. Senderowicz and E. A. Sausville, Preclinical and clinical development of cyclin-dependent kinase modulators. J. Natl. Cancer Inst. 92, 376-387 (2000).

17. H. H. Xiao, Y. Makeyev, J. Butler, B. Vikram and W. A. Franklin, 7-Hydroxystaurosporine (UCN-01) preferentially sensitizes cells with a disrupted TP53 to gamma radiation in lung cancer cell lines. Radiat. Res. 158, 84-93 (2002).

18. M. Bache, S. Pigorsch, J. Dunst, P. Wurl, A. Meye, F. Bartel, H. Schmidt, F. W. Rath and H. Taubert, Loss of $\mathrm{G}_{2} / \mathrm{M}$ arrest correlates with radiosensitization in two human sarcoma cell lines with mutant p53. Int. J. Cancer 96, 110-117 (2001).

19. A. Blasina, B. D. Price, G. A. Turenne and C. H. McGowan, Caffeine inhibits the checkpoint kinase ATM. Curr. Biol. 9, 1135-1138 (1999).

20. J. N. Sarkaria, E. C. Busby, R. S. Tibbetts, P. Roos, Y. Taya, L. M. Karnitz and R. T. Abraham, Inhibition of ATM and ATR kinase activities by the radiosensitizing agent, caffeine. Cancer Res. 59, 43754382 (1999).

21. A. Matsuda, M. Fukushima, Y. Wataya and T. Sasaki, A new antitumor nucleoside, 1-(3-C-ethynyl- $\beta$-D-ribo-pentofuranosyl)cytosine (ECyd), is a potent inhibitor of RNA synthesis. Nucleosid. Nucleotid. 18, 811-814 (1999).

22. A. Azuma, A. Matsuda, T. Sasaki and M. Fukushima, 1-(3-C-Ethynyl- $\beta$-D-ribo-pentofuranosyl)cytosine (ECyd, TAS-106) 1: antitumor effect and mechanism of action. Nucleosid. Nucleotid. Nucleic Acid 20, 609-619 (2001).

23. M. Osaki, S. Tatebe, A. Goto, H. Hayashi, M. Oshima and H. Ito, 5Fluorouracil (5-FU) induced apoptosis in gastric cancer cell lines: Role of the p53 gene. Apoptosis 2, 221-226 (1997).

24. W. Chaung, L. J. Mi and R. J. Boorstein, The p53 status of Chinese hamster V79 cells frequently used for studies on DNA damage and DNA repair. Nucleic Acids Res. 25, 992-994 (1997). 